\title{
Cartas de aptidão para sistemas alternativos de esgotamento sanitários
}

\author{
Suitability maps for alternative systems of sanitary sewage
}

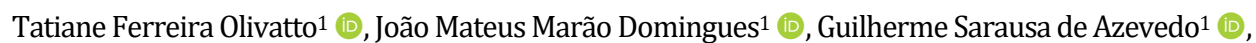
Franciane Mendonça dos Santos ${ }^{1}$ (D), José Augusto Di Lollo² (D), Reinaldo Lorandi1 ${ }^{1}$ (D), Luiz Eduardo Moschini ${ }^{1}$ (D)

${ }^{1}$ Universidade Federal de São Carlos, São Carlos, SP, Brasil. E-mails: tatianeolivatto@yahoo.com.br, jmmarao@gmail.com, guisarausa@gmail.com, franciane.mds@usp.br, lorandir@gmail.com, lemoschini@ufscar.br 2Universidade Estadual Paulista “Júlio de Mesquita Filho”, Ilha Solteira, SP, Brasil. E-mail: jose.lollo@unesp.br

Como citar: Olivatto, T. F., Domingues, J. M. M., Azevedo, G. S., Santos, F. M., Di Lollo, J. A., Lorandi, R., \& Moschini, L. E. (2021). Cartas de aptidão para sistemas alternativos de esgotamento sanitários. Revista de Gestão de Água da América Latina, 18 , e12. https://doi.org/10.21168/rega.v18e12

RESUMO: O serviço de saneamento básico no Brasil apresenta por vezes condições precárias, especialmente nas regiões rurais ou isoladas. Esta Pesquisa trabalho apresenta cartas de aptidão para a implantação de três técnicas distintas de esgotamento sanitário para a área rural da Bacia do Ribeirão do Meio (município de Leme-SP). A partir da caracterização geotécnica da bacia, e de análises das informações foram identificadas as áreas mais favoráveis para a implantação de tanques sépticos, fossas e lagoas de disposição de águas residuárias. As operações de álgebra de mapas realizadas consideram o substrato rochoso, os materiais inconsolidados, condições de circulação de água, feições geodinâmicas, relevo e clima. Os atributos utilizados foram classificados variando entre condições favoráveis à restritivas. As cartas produzidas não sugerem qual a melhor técnica a ser adotada, mas as condições para implantação de cada uma delas. Os resultados obtidos indicam que a área apresenta aptidão predominantemente moderada para adoção de tanques sépticos e equilíbrio entre condições favoráveis e moderadas para fossas e lagoas de águas residuárias.

Palavras-chave: Cartografia Temática; Geologia Ambiental; Saneamento Básico; Saneamento Ambiental.

ABSTRACT: The precariousness is a common situation for basic sanitation service in Brazil, especially in rural and isolated regions. This paper presents a set of charts defining conditions for of three different alternative sanitary sewage techniques for the rural area of Ribeirão do Meio Watershed (municipality of Leme-SP). Based on geotechnical characterization of the basin, we developed analysis identifying the most favorable areas for septic tanks, sumps and lagoons for wastewater disposal implementation. The map algebra operations consider the rocks, soils, conditions of water circulation, geodynamic features, relief and climate conditions. The attributes used were classified varying between favorable and restrictive conditions. The obtained charts do not suggest the best technique to be adopted, but the conditions for implementing each one. Results indicate that the area shows predominantly moderate conditions to septic tanks implementation, and a balance between favorable and moderate conditions for sumps and lagoons for wastewater disposal. The more decisive attributes in the area came from rocks conditions.

Keywords: Thematic Cartography; Environmental Geology; Basic Sanitation; Environmental Sanitation.

\section{INTRODUÇÃO}

Os serviços de saneamento envolvem um conjunto de atividades relacionadas ao tratamento de água e esgoto, abastecimento de água, destinação das águas pluviais e lixo urbano (Agência Nacional de Águas e Saneamento Básico, 2019). Segundo o Instituto Trata Brasil (2018), as condições de saneamento no país são precárias com mais da metade da população não tendo coleta de esgoto. Além disso, 62,5\% do esgoto brasileiro não passam por tratamento antes de seu lançamento no destino final (Instituto Trata Brasil, 2018). A carência de tais serviços favorece tanto a transmissão de doenças cíclicas feco-oral, quanto à proliferação de doenças infecciosas (Soares et al., 2002).

Em um levantamento das obras de infraestrutura paralisadas no Brasil, foi constatado que 429 eram de saneamento básico, compreendendo cerca de $60 \%$ dos projetos que visam melhorar o serviço

Recebido: Março 10, 2021. Revisado: Junho 21, 2021. Aceito: Agosto 11, 2021. 
de tratamento de água e coleta de esgoto. As causas técnicas predominantes em tais paralizações são metodologia inadequada e falta de planos e projetos tecnicamente embasados (Conselho Federal de Administração, 2019).

Nas áreas rurais e áreas isoladas os riscos associados à fragilidade sanitária são mais sérios, acrescendo a contaminação dos recursos hídricos por manejo indevido de águas residuárias (Pinheiro et al., 2014). As alternativas para tais comunidades são soluções técnicas como fossas sépticas, em função de seu custo, porém exigindo cuidados em sua implantação (Instituto Trata Brasil, 2018). Também no exterior, a adoção de sistemas alternativos têm sido a tônica da prevenção da poluição devida a esgoto (Christopherson, 2001; Gu et al., 2016; Wójtowicz-Wróbel, 2018; Cheng et al., 2020).

Segundo Brasil (2014) estima-se que um volume de 4,8 bilhões de litros de esgoto é lançado na zona rural. Costa \& Guilhoto (2014) estimaram que a adoção de sistemas locais de tratamento adequados poderia evitar cerca de 250 mortes e 5,5 milhões de infecções causados por doenças diarreicas. Além tais benefícios, tais sistemas poderiam reduzir a poluição dos cursos d'água em 250 mil toneladas de DBO e 173 mil toneladas de nutrientes ao ano, e proporcionar, para cada $R \$ 1,00$ investido, um investimento de $\mathrm{R}$ \$ 4,69 em produção e R\$ 2,55 em PIB (Costa \& Guilhoto, 2011a, 2011b).

Para atender pequenos empreendimentos ou mesmo famílias que vivem na zona rural, as fossas e os tanques sépticos representam as melhores alternativas em termos de investimento, manutenção e volume de esgoto a ser tratado (Silva, 2014; Silva et al., 2018; Galindo et al., 2019). Tais sistemas apresentam ainda grande potencial de uso em sistemas irrigados de pequeno a médio porte (Novaes et al., 2002; Brasil, 2014).

No interior do Estado de São Paulo, o índice de adequação de esgotamento sanitário na área rural varia entre 30 a 60\% dos domicílios na área rural, enquanto na área urbana tal índice é superior a $90 \%$ (Landau \& Moura, 2016). Nessas condições, soluções locais de baixo custo toram-se alternativas ainda mais importantes, sendo fundamental a avaliação de sua eficiência (Andrade et a., 2017) e a avaliação das condições locais para que se evite contaminação de solo e mananciais de superfície e subsuperfície.

Os cuidados quanto à seleção do local são bastante similares quando se trata de tanques e fossas sépticas (Associação Brasileira de Normas Técnicas, 1997; Brasil, 2014; Silva, 2014). Para lagoa de disposição de águas residuárias, os cuidados são maiores, uma vez que o empreendimento apresenta maior porte e maior potencial de dano ambiental (Associação Brasileira de Normas Técnicas, 1992; Companhia de Saneamento Básico do Estado de São Paulo, 2009).

Para Lopes \& Saldanha (2016), a preservação e melhoria das condições ambientais devem ser baseadas em levantamentos e estudos prévios sobre os principais elementos e condicionantes do meio físico. Outros autores destacam a relação entre métodos de tratamento e processos construtivos e os benefícios de proteção ambiental (Oldenkamp et al., 2014; Lu et al., 2016).

Em situações em que diferentes variáveis ambientais são consideradas em conjunto, as análises multicritério, baseadas em Sistemas de Informações Geográficas têm sido usadas com bastante sucesso em diversos trabalhos (Kalbar et al., 2012; Li et al., 2017; Piga et al., 2017; Costa et al., 2018; Urban \& Isaac, 2018). Considerando tal panorama, são apresentadas cartas de aptidão para implantação de tanque séptico, fossa e lagoa de disposição de águas residuárias na área rural da Bacia Hidrográfica do Ribeirão do Meio (BHRM) no município de Leme (São Paulo).

Em Cartografia Geotécnica, as Cartas de Aptidão constituem documentos cartográficos de síntese que apresentam e classificam os terrenos em termos das condições para implantação de determinado empreendimento. Podem ser citados alguns exemplos como Cartas de Aptidão para Obras Viárias, para Obras Enterradas, para Implantação de Aterros Sanitários, entre outras (Zuquette, 1987; Lollo, 1991; Souza \& Sobreira, 2015).

No presente trabalho, o desenvolvimento de tais análises se deu a partir de atributos do meio físico que foram classificados e combinados de forma a indicar as áreas mais favoráveis para a implantação das soluções de esgotamento sanitário consideradas. A combinação dos atributos foi realizada via álgebra de mapas executada em Sistema de Informações Geográficas (SIG), de forma a fornecer subsídios para compreensão da dinâmica do meio físico tendo em vista a implantação de tecnologias alternativas de esgotamento sanitário na BHRM.

A adoção de sistemas alternativos descentralizados para esgotamento sanitário permite importante redução de custos no atendimento de populações rurais ou em áreas periurbanas (Massoud et al., 2009). Além disso, seus projetos e sistemas construtivos são mais simplificados, portanto aptos a atender pequenas comunidades (Cornelli, 2014). 
Como se terá oportunidade de verificar, o conjunto de atributos tratados na análise de aptidão para as três opções consideradas é bastante semelhante o que dá a opção à comunidade e ao corpo técnico envolvido de selecionar aquele que melhor se adeque às necessidades específicas da comunidade ou empreendimento local.

\section{CARACTERIZAÇÃO DA ÁREA DE ESTUDO}

A BHRM localiza-se na região centro-leste do estado de São Paulo, entre as coordenadas UTM 246.754 - 267.125 m E e 7.545.578 e 7.555.696 m N, na Zona 23 Sul (Figura 1). A Bacia Hidrográfica possui área de drenagem de 249,05 km², ordem de ramificação 4, segundo a classificação de Strahler (1952), e está inserida na Unidade de Gerenciamento de Recursos Hídricos do Rio Mogi Guaçu - UGRHI 09. O Ribeirão do Meio nasce a oeste do município de Leme (SP) e sua foz localiza-se no Rio Mogi Guaçu.

A região abrange grande parte do município de Leme, inclusive toda sua área urbana, e pequena parcela dos municípios de Pirassununga e Araras. Segundo o Instituto Brasileiro de Geografia e Estatística (2020) a população estimada para estes municípios foi respectivamente 104.346 habitantes; 76.877 habitantes; e 135.506 habitantes.

As mudanças no uso do solo mais marcantes ocorridas na bacia se deram nas áreas não urbanas, com forte avanço da cultura sucroalcooleira. Os dados populacionais oficiais mostram que $2,06 \%$ da população estão na parcela rural da bacia, em núcleos rurais como o Bairro Taquari, Taquari-Ponte, Recanto da Colina, Ibicatu e Bairro Caju (Instituto Brasileiro de Geografia e Estatística, 2010; Leme, 2018 b). No entanto, a existência de uma parcela muito significativa da população local (25\%) que atua nas atividades ligadas à agricultura, faz com que essa parcela da população passe todo seu dia de trabalho no campo (Leme, 2018b).

O clima predominante do município segundo a classificação de Köppen é o Cwa que se caracteriza como subtropical de inverno seco e verão quente (Alvares et al., 2014). 0 período chuvoso ocorre de setembro a março, com valores mínimos e máximos de 85 e $258 \mathrm{~mm}$, enquanto o período seco ocorre de abril a agosto, com mínima de $27 \mathrm{~mm}$ e máxima de $77 \mathrm{~mm}$. A temperatura média máxima é $24.5^{\circ} \mathrm{C}$ e mínima 18.5C (Centro Integrado de Informações Agrometereológicas, 2009).

Geologicamente a área está inserida na compartimentação geotectônica Cráton Paraná, na Província Estrutural do Paraná (Hasui, 2012). Na bacia ocorrem sete unidades litoestratigráficas (Lollo, 1991; Lorandi \& Lollo, 2016), conforme se pode observar na Figura 2.
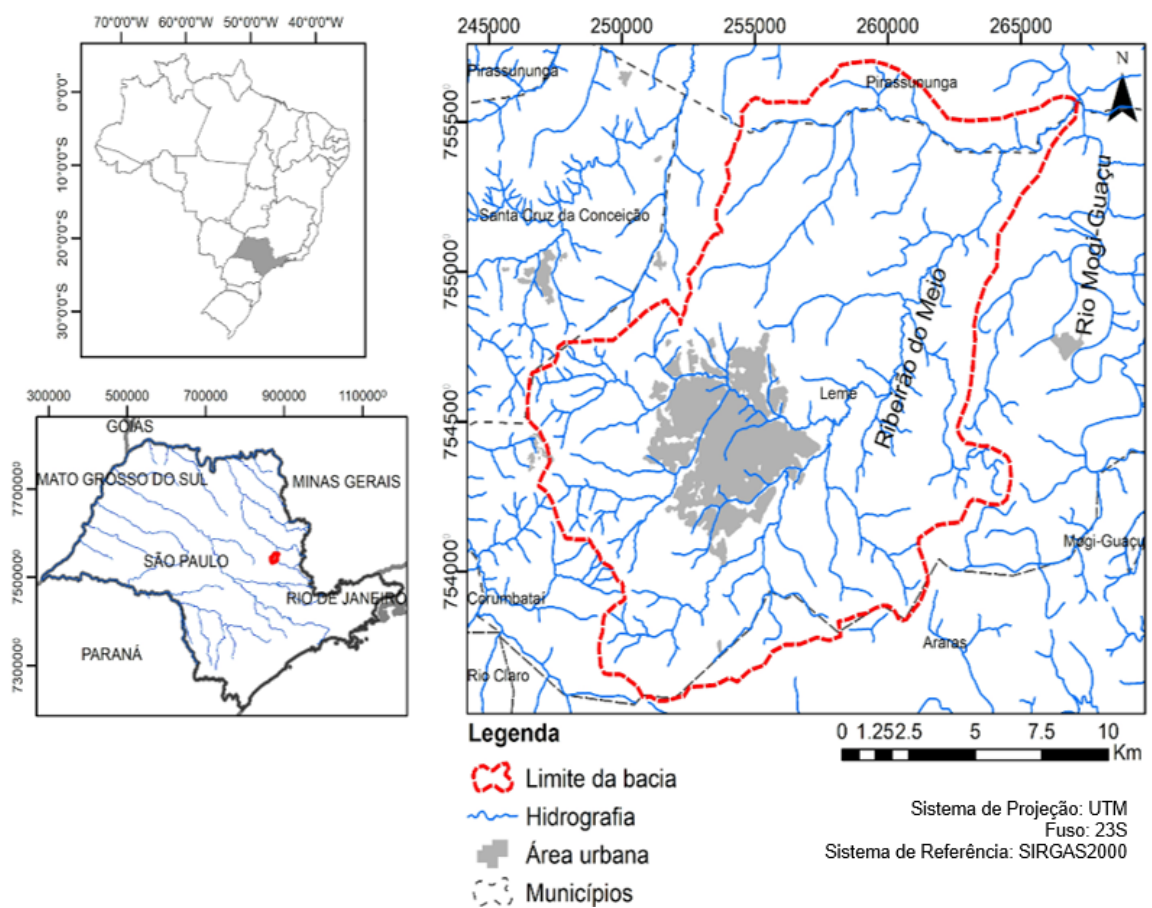

Figura 1 - Localização da bacia hidrográfica do Ribeirão do Meio. Fonte: Autores (2020) 


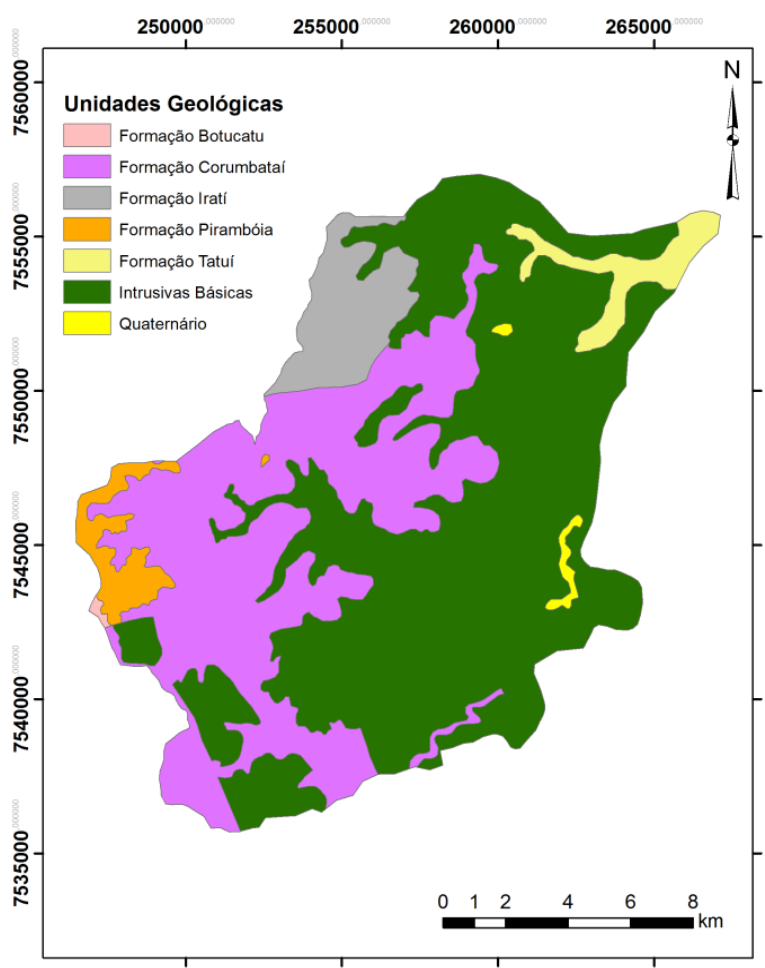

Figura 2 - Unidades Geológicas presentes na bacia hidrográfica do Ribeirão do Meio.

A área apresenta três formações geológicas de idade Permiana da Bacia do Paraná. A Formação Irati é composta por siltitos e folhelhos e ocorre na porção NW da bacia, a Formação Tatuí na área é composta por siltitos arenosos, ocorrendo nos fundos de vale na porção NE, e a Formação Corumbataí é constituída por siltitos, e secundariamente argilitos e folhelhos em sua porção inferior. Na seção superior, ocorrem argilitos e arenitos finos.

A Formação Pirambóia, de idade Triássica, é composta por arenitos médios a muito finos, quartzosos, com intercalações de siltitos e argilitos. Na seção inferior os arenitos são mais finos e argilosos. De idade Juro-Cretácica, a Formação Botucatu é constituída por arenitos finos a médios; friáveis a bem silicificados, com grãos arredondados e foscos. A Formação Serra Geral e Rochas Intrusivas Básicas associadas, também de idade Juro-Cretácica, é constituída por derrames de lavas basálticas, toleíticas, de textura afanítica e intrusivas (diques e soleiras), contendo intercalações de lentes e camadas arenosas de textura fina a média com estratificação cruzada.

Sedimentos Quaternários ocorrem na bacia na forma de planícies aluvionares bem desenvolvidas, com depósitos de várzeas e terraços, constituídos de areias, argilas e cascalhos.

Em termos dos condicionantes para implantação dos sistemas de esgotamento sanitário considerados, as unidades geológicas sedimentares de textura arenosa média a grosseira apresentam condições mais favoráveis à infiltração, podendo se constituir em áreas com maior potencial de contaminação de mananciais subsuperficiais. Tal condição é mais grave nas áreas de ocorrência dos sedimentos quaternários.

Nas áreas de ocorrência das unidades sedimentares de textura argilosa, siltosa, e arenosa fina, e nas áreas de onde ocorrem as unidades magmáticas; as condições de infiltração de fluidos são mais favoráveis à proteção dos mananciais subsuperficiais.

Segundo Ross \& Moroz (1997) a geomorfologia da Bacia Hidrográfica abrange a Unidade Morfoestrutural da Bacia Sedimentar do Paraná; Unidade Morfoescultural da Depressão Periférica Paulista e Depressão Moji-Guaçu.

As características geológicas e geotécnicas destes materiais associadas à declividade da Bacia e à natureza destes materiais refletem na infiltração e escoamento superficial, desencadeando processos de erosão (Failache \& Zuquette, 2015). 


\section{MATERIAIS E MÉTODOS}

A metodologia adotada neste trabalho se baseou na proposta de Zuquette \& Gandolfi (2004), que definiram os atributos e respectivas classes de aptidão para implantação de sistemas alternativos de esgotamento sanitário (tanques sépticos, fossas e lagoas de disposição de águas residuárias).

Os atributos considerados podem ser classificados em termos dos componentes ambientais substrato rochoso, materiais inconsolidados, condições de circulação de água, feições, relevo e clima, sendo cada atributo classificado como restritivo, severo, moderado e favorável; de acordo com sua influência em cada caso. As unidades de materiais inconsolidados (solos e sedimentos) presentes na área estão representadas na Figura 3.

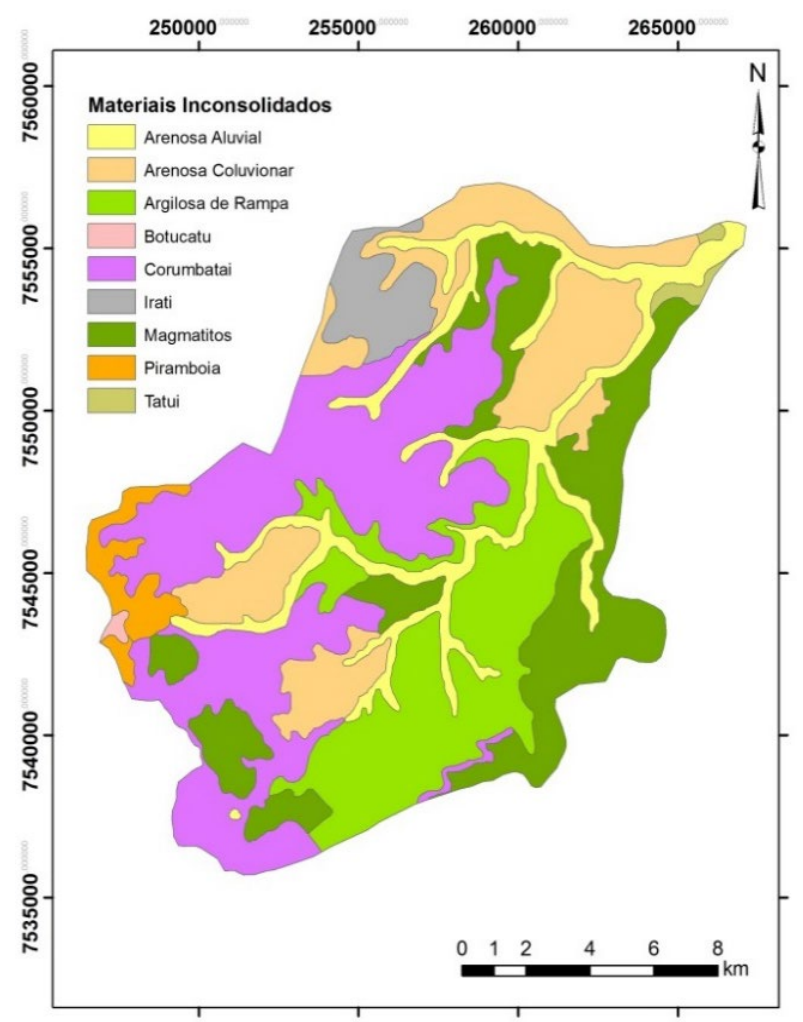

Figura 3 - Carta de Materiais Inconsolidados da bacia hidrográfica do Ribeirão do Meio.

Como já comentado, as áreas de ocorrência das unidades geológicas sedimentares de textura arenosa representam condições com maior potencial de infiltração, portanto, maiores riscos de contaminação. No entanto, as unidades de materiais inconsolidados sobrepostas a essas unidades geológicas apresentam espessos perfis de alteração (chegando a ultrapassar vinte metros de espessura) o que resulta numa profundidade maior para a superfície que delimita o substrato rochoso. Isso reduz o potencial de contaminação dos mananciais de subsuperfície, uma vez que solos mais espessos (mesmo quando apresentam textura arenosa) retardam a percolação e podem reter parte significativa das substâncias contaminantes.

Já nas áreas de ocorrência das unidades geológicas sedimentares de textura fina e das unidades magmáticas, as espessuras dos perfis de solos são menores (raramente ultrapassando cinco metros), porém, sua textura fina resulta menor permeabilidade do meio, e solos com mineralogia mais favorável à retenção de contaminantes.

Nas áreas de ocorrência das unidades retrabalhadas, as condições de formação e a granulometria dos sedimentos também tem papel fundamental nas condições de percolação e potencial de contaminação. Enquanto as unidades de textura arenosa (Arenosa Aluvial e Arenosa Coluvionar) apresentam maiores coeficientes de permeabilidade e maiores espessuras, a unidade coluvionar de textura argilosa (Argilosa de Rampa) apresenta menores espessuras, menores coeficientes de permeabilidade, e mineralogia favorável à retenção de contaminantes.

Em função de disponibilidade e resolução espacial dos dados necessários, alguns critérios necessitaram adaptações de classificação, enquanto outros foram desconsiderados. Neste 
sentido, foram desconsiderados os critérios de direções do fluxo de água na zona saturada, fluxo superficial, zonas de recarga, condições de drenagem, limites entre bacias, zonas úmidas e zonas de inundação, por falta de registro de tais informações.

A desconsideração da presença de zonas úmidas e zonas de inundação não acarretam mudanças significativas nos resultados, já que tais locais não seriam considerados para a implantação dos empreendimentos por normalmente situarem-se em áreas de preservação permanente. Limites entre bacias são locais que favorecem a dispersão de fluxos em mais de uma direção, razão pela qual raramente se considera implantar esse tipo de sistemas nesses locais.

A não consideração das condições de fluxo superficial e subsuperficial, das condições de drenagem, e de áreas de recarga de aquíferos, podem vir a permitir que sejam caracterizadas como aptas áreas cujas condições locais favoreçam o fluxo de contaminantes. No entanto, para decisões de projeto quanto à implantação dos sistemas considerados, levantamentos de detalhe serão necessários, permitindo que tais situações sejam identificadas.

A ocorrência de matacões também foi excluída da análise, uma vez que não se tem registro de matacões na área na BHRM, o mesmo valendo para o critério de salinidade, em virtude da característica não salina dos recursos hídricos da região. As feições geodinâmicas (movimentos gravitacionais de massa, e subsidências) não foram consideradas por não existirem na área. Assim, dentre as feições geodinâmicas, foram considerados os processos erosivos, distinguidos entre favorável e severo, refletindo a ausência ou presença dos mesmos.

Em função da disponibilidade de dados e informações, o atributo de $\mathrm{pH} / \Delta \mathrm{pH}$ foi tratado apenas como $\mathrm{pH}$, especialmente porque as variações desses atributos eram muito reduzidas para se considerar o $\Delta \mathrm{pH}$. Para a determinação da profundidade da zona saturada, foi adotada a profundidade do substrato rochoso, uma vez que os dados locais mostram que é a ocorrência do substrato rochoso que controla esse nível na área.

0 único atributo com forte diferença de critério para a seleção de áreas aptas à implantação de tanques sépticos, fossas e lagoa de disposição de águas residuárias é a profundidade do substrato rochoso, especialmente porque os intervalos de classes de profundidade disponíveis não coincidiam com os intervalos propostos por Zuquette \& Gandolfi (2004). Consequentemente, como havia convergência nas classes de atributos para lagoa e fossa, foram produzidos dois mapas de aptidão: um para lagoas e fossas e outro para tanques.

Para fins de álgebra de mapas, as classes receberam os seguintes valores numéricos: 4 para favorável, 3 para severo, 2 para moderado e 1 para restritivo. De acordo com a metodologia proposta por Zuquette e Gandolfi (2004), aplica-se o mesmo peso a todos os atributos.

A soma ponderada das classes de atributos, resultou a reclassificação das áreas segundo os quatro níveis de aptidão. Estas operações, bem como a assimilação dos valores das classes foram realizadas em ambiente SIG.

Apesar de datar de 2004, o trabalho de Zuquette \& Gandolfi (2004) não contempla aplicação da metodologia, e não se tem registro de outra aplicação da proposta para seleção de áreas para implantação de sistemas alternativos de esgotamento sanitário. Por essa razão, optou-se por manter a proposta original (pesos iguais para todos os componentes e atributos ambientais) opção considerada mais adequada a um teste de aplicação da proposta.

Como não havia aplicações da proposta em outras áreas, cujos resultados pudessem comparados a esse trabalho, os resultados foram comparados aos trabalhos de Sardinha (2005) (análise para implantação de empreendimentos potencialmente poluidores na bacia), Costa et al (2018) (seleção de áreas para implantação de aterros sanitários na bacia), e Piga et al (2017) (avaliação do potencial de contaminação das águas subterrâneas em bacia limítrofe com as mesmas condições do meio físico).

A Tabela 1 apresenta os componentes ambientais, seus atributos, e respectivas classes utilizadas na análise. A atribuição dos pesos foi baseada na proposta original (Zuquette \& Gandolfi, 2004), com algumas adaptações já comentadas para as situações nas quais determinadas classes não ocorressem na bacia, ou que certo atributo não estivesse disponível.

Os dados utilizados foram oriundos dos trabalhos de Lollo (1991); Ross \& Moroz (1997); Failache \& Zuquette (2015) e Lorandi \& Lollo (2016). A escala de trabalho adotada foi 1:50.000 em função dos dados originais se encontrarem nessa escala. Os dados de declividade foram produzidos a partir de Modelos Digitais de Elevação Alos Palsar. 
Tabela 1 - Classificação dos atributos segundo os componentes ambientais considerados

\begin{tabular}{|c|c|c|c|c|c|c|}
\hline \multirow{2}{*}{ Componente } & \multirow{2}{*}{ Atributo } & \multirow{2}{*}{$\begin{array}{l}\text { Aptidão } \\
\text { Obtida }\end{array}$} & \multicolumn{4}{|c|}{ CLASSES } \\
\hline & & & $\begin{array}{c}\text { Favorável } \\
(4)\end{array}$ & $\begin{array}{c}\text { Moderada } \\
\text { (3) }\end{array}$ & $\begin{array}{c}\text { Severa } \\
(2)\end{array}$ & $\begin{array}{c}\text { Restritiva } \\
\text { (1) }\end{array}$ \\
\hline \multirow{3}{*}{$\begin{array}{l}\text { Substrato } \\
\text { Rochoso }\end{array}$} & Litologia & Todas* & - & - & Arenitos & Calcários \\
\hline & \multirow{2}{*}{$\begin{array}{l}\text { Profundidade do } \\
\text { Substrato Rochoso } \\
\text { (m) }\end{array}$} & $\begin{array}{c}\text { Lagoas/ } \\
\text { Fossas }\end{array}$ & $>5$ & $5-2$ & $5-2$ & $<2$ \\
\hline & & $\begin{array}{l}\text { Tanque } \\
\text { Séptico }\end{array}$ & $>10$ & $10-5$ & $5-2$ & $<2$ \\
\hline \multirow{7}{*}{ 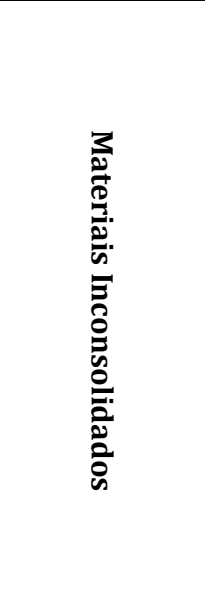 } & Textura & Todas* & $\begin{array}{c}\text { Silto-arenosa } \\
\text { ou Argilo- } \\
\text { arenosa } \\
\end{array}$ & - & $\begin{array}{c}\text { Areno- } \\
\text { argilosas ou } \\
\text { Siltosas } \\
\end{array}$ & $\begin{array}{c}\text { Arenosa ou } \\
\text { Argilosa }\end{array}$ \\
\hline & Variação Vertical & Todas* & Gradativa & Gradativa & Homogênea & Homogênea \\
\hline & Mineralogia & Todas* & $\begin{array}{l}\text { Minerais de } \\
\text { argila }\end{array}$ & - & - & $\begin{array}{l}\text { Minerais } \\
\text { Inertes }\end{array}$ \\
\hline & pH & Todas* & $>4$ & $>4$ & $>5$ & $<4$ \\
\hline & $\begin{array}{l}\text { CTC } \\
(\mathrm{cmol}(+) / \mathrm{kg}) \\
\end{array}$ & Todas* & $>15$ & $10-15$ & $<10$ & $>5$ \\
\hline & Colapsibilidade & Todas* & Não & - & - & - \\
\hline & Erodibilidade & Todas* & Não & Não & - & - \\
\hline \multirow{3}{*}{ Águas } & \begin{tabular}{|l|} 
Profundidade da \\
Zona Saturada (m)
\end{tabular} & Todas* & $>10$ & $10-5$ & $5-2$ & $>2$ \\
\hline & \begin{tabular}{|l|} 
Condutividade \\
Hidráulica $(\mathrm{cm} / \mathrm{s})$ \\
\end{tabular} & Todas* & $10^{-4}-10^{-5}$ & $10^{-3-10^{-4}}$ & $>10^{-3}$ & $>10^{-2}$ \\
\hline & $\begin{array}{ll}\text { Distância } & \text { para } \\
\text { Fontes e Poços }(\mathrm{m})\end{array}$ & Todas* & $>100$ & $>50$ & $<50$ & $<30$ \\
\hline Feições & Erosão & Todas* & Não & Não & - & - \\
\hline Relevo & Declividade (\%) & Todas* & $<10$ & $10-15$ & $15-30$ & $>30$ \\
\hline \multirow[t]{2}{*}{ Climático } & $\begin{array}{l}\text { Evapotranspiração } \\
(\mathrm{mm})\end{array}$ & Todas* & $\begin{array}{c}\text { Alta } \\
(>1000 \mathrm{~mm})\end{array}$ & \begin{tabular}{|c|}
$\begin{array}{c}\text { Intermediário } \\
(800-1000 \\
\mathrm{mm})\end{array}$ \\
\end{tabular} & $\begin{array}{l}\text { Baixo (600 - } \\
800 \mathrm{~mm})\end{array}$ & $\begin{array}{l}\text { Muito Baixo } \\
(<600 \mathrm{~mm})\end{array}$ \\
\hline & \begin{tabular}{|l} 
Pluviosidade \\
(mm)
\end{tabular} & Todas* & $<1500$ & - & - & $>3000$ \\
\hline
\end{tabular}

* Todas = tanques sépticos, fossas e lagoas de disposição de águas residuárias. Fonte: Adaptado de Zuquette e Gandolfi (2004). *_” = não ocorre.

\section{RESULTADOS E DISCUSSÕES}

Na etapa inicial, os componentes foram classificados segundo as quatro classes de aptidão utilizadas, resultando as cartas apresentadas na Figura 4, onde se pode observar que, para a área estudada, relevo, feições geodinâmicas, e clima (itens B, E, e F) são majoritariamente favoráveis à implantação dos sistemas considerados.

Para materiais inconsolidados (C) e condições de circulação de água (D) se nota importante percentagem da área classificada como "favorável" e "moderada", enquanto para o substrato rochoso (A) a classe "severa" tem grande expressão, seja para tanques, fossas ou lagoas. 

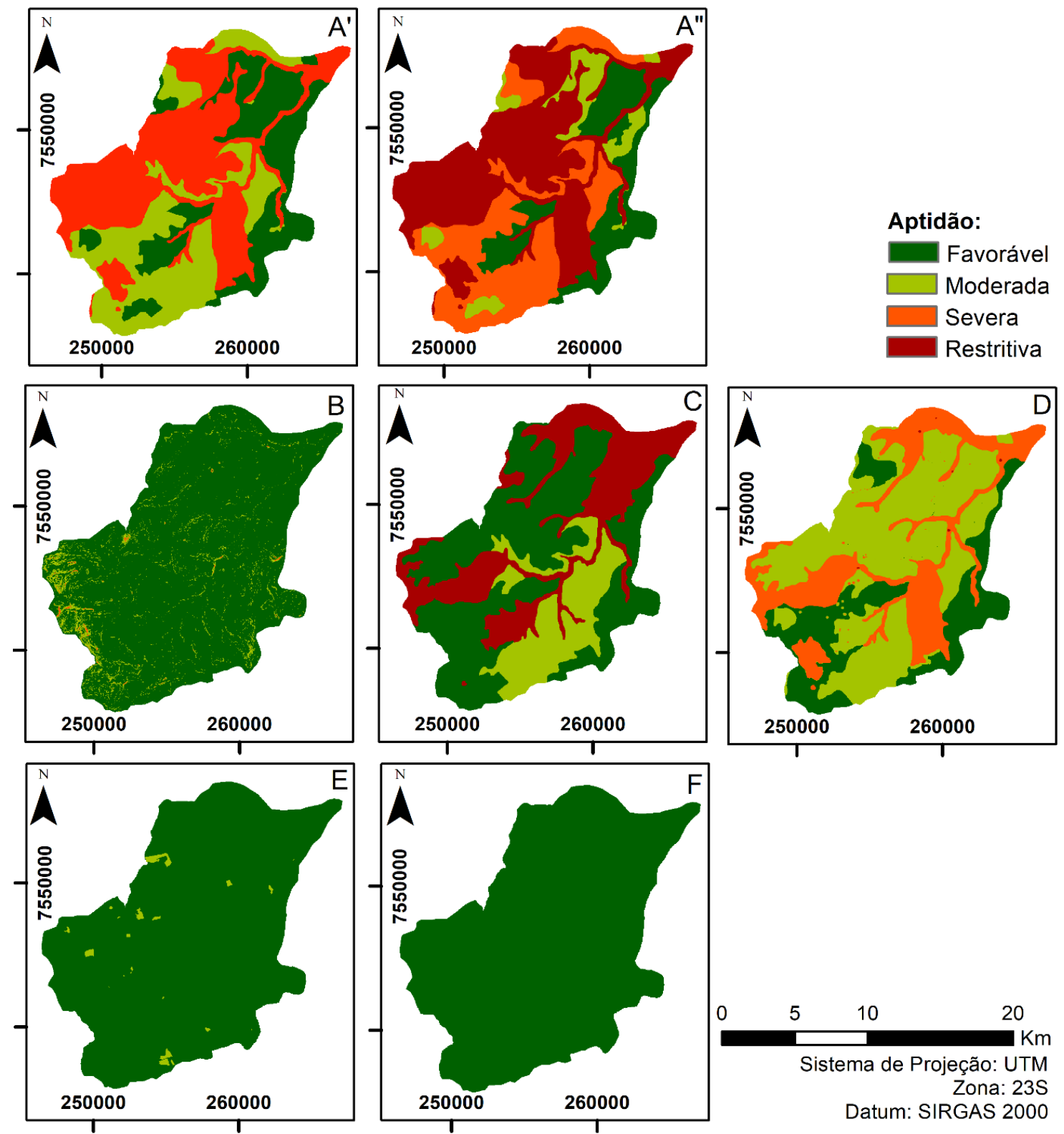

Figura 4 - Cartas com as classes dos componentes ambientais. A' - substrato rochoso (litologia e profundidade do substrato) para tanques, A" para fossas e lagoas; B - relevo (declividade); C - material inconsolidado (textura, variação vertical, mineralogia, pH, CTC, colapsividade e erodibilidade); D - condições de circulação de água (profundidade da zona saturada, condutividade hidráulica e distância de poços); E - feições geodinâmicas (erosão); F - clima (precipitação e evapotranspiração). Fonte: Autores (2020).

As variações nas classes do substrato rochoso se devem essencialmente ao atributo profundidade do substrato rochoso (destacadas na Figura 5), enquanto os demais atributos apresentam as mesmas classes tanto para tanques sépticos, quanto para fossas e lagoas de disposição de águas residuárias.

Na Figura 5 é possível identificar esta diferenciação, sendo que para fossas e lagoas incluem-se as classes restritiva, severa, moderada e favorável. Para tanques a classe severa é inexistente. Além disso, algumas regiões consideradas moderadas para fossas e lagoas foram classificadas como favoráveis para a instalação de tanques.

0 atributo profundidade do substrato rochoso se mostra menos favorável à implantação dos sistemas porque nas áreas de ocorrência da Formação Corumbataí e das rochas Intrusivas Básicas predominam perfis menos desenvolvidos de solos, e a profundidade do substrato raramente ultrapassa $5 \mathrm{~m}$. Além disso, para implantação de lagoas e fossas a proposta indica maiores profundidades para classificar as áreas como favorável e moderada.

Apesar de tais condições menos favoráveis em relação ao substrato rochoso, outros atributos favoráveis, em particular dos materiais inconsolidados e de declividade dos terrenos, permitiram que 
na álgebra de mapas que considerou a combinação de todos os atributos, os resultados tenham sido mais favoráveis.

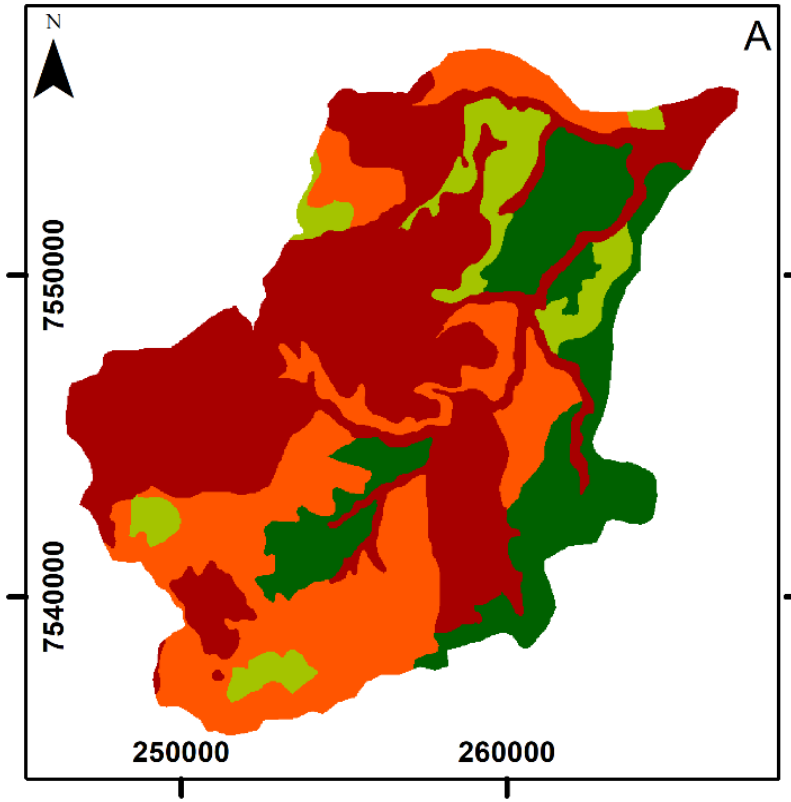

Aptidão:

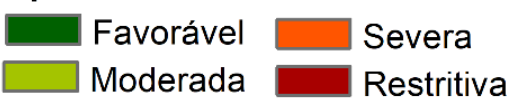

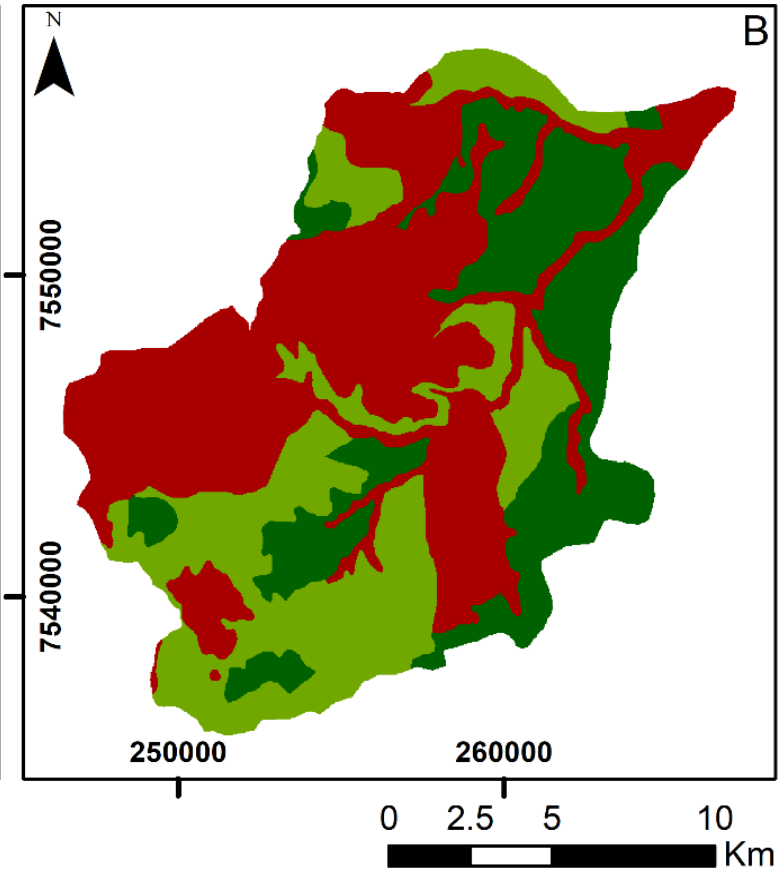

Sistema de Projeção: UTM

Zona: $23 S$

Datum: SIRGAS 2000

Figura 5 - Classes de aptidão: profundidade do substrato rochoso. (A) lagoas e fossas e (B) tanques sépticos. Fonte: Autores (2020)

Na etapa seguinte foi realizada a álgebra de mapas, segundo uma operação de soma ponderada. Em função do uso dos mesmos atributos com a mesma ponderação, os resultados para Aptidão para a implantação de Fossas e para Lagoas de Disposição de Águas Residuárias foram iguais, sendo apresentados na Figura 6A, enquanto a Figura 6B apresenta a Carta de Aptidão para implantação de Tanques Sépticos.

$\mathrm{Na}$ apresentação dos resultados, foram excluídas as áreas correspondentes às Macrozonas Urbana, Expansão Urbana, Proteção Ambiental e Zona Especial do Aeroporto, conforme indicadas no Anexo II da minuta da Revisão do Plano Diretor de Leme (Leme, 2018a) por se tratar de áreas que, ou são atendidas pela rede de coleta de esgoto do município, ou serão atendidas conforme o desenvolvimento imobiliário do município.

Os resultados obtidos não apresentaram áreas restritivas para a implantação dos equipamentos citados. A Bacia do Ribeirão do Meio apresenta regiões que variam entre severas a favoráveis para estas implantações. Mesmo com os resultados da álgebra de mapas não retornando áreas na classe "restritiva", as Áreas de Preservação Permanente (APP) foram classificadas como tal, por se tratarem de áreas com restrições legais para a implantação deste tipo de equipamento, em função do risco de contaminação dos corpos d'água.

As características do Substrato Rochoso e dos Materiais Inconsolidados foram determinantes para a classificação da aptidão para a instalação dos sistemas de tratamento discutidos, principalmente, para identificar locais com capacidade de suporte adequada, no caso das Lagoas de Disposição de Águas Residuais, e cuidados para evitar contaminações no caso dos três tipos de instalações (Zuquette \& Gandolfi, 2004).

Os locais menos favoráveis para a implantação de Tanques Sépticos, Lagoas de Águas Residuárias e Fossas se encontram no extremo oeste e nordeste da bacia hidrográfica e também ao longo dos cursos d'água, majoritariamente na porção norte (Figura 6).

Nesses locais, predominam substratos rochosos com características arenosas e porosas, como as formações Botucatu e Pirambóia a oeste e a formação Tatuí a nordeste. No fundo dos vales, proximidades dos cursos d'água, ocorrem diferentes formações geológicas. Em todas essas regiões o 
substrato é pouco profundo (até 2 metros), o que as tornam restritivas. Ainda na porção oeste, ocorrem as maiores declividades da bacia hidrográfica, chegando a superar $30 \%$, o que também é restritivo para as alternativas sanitárias.
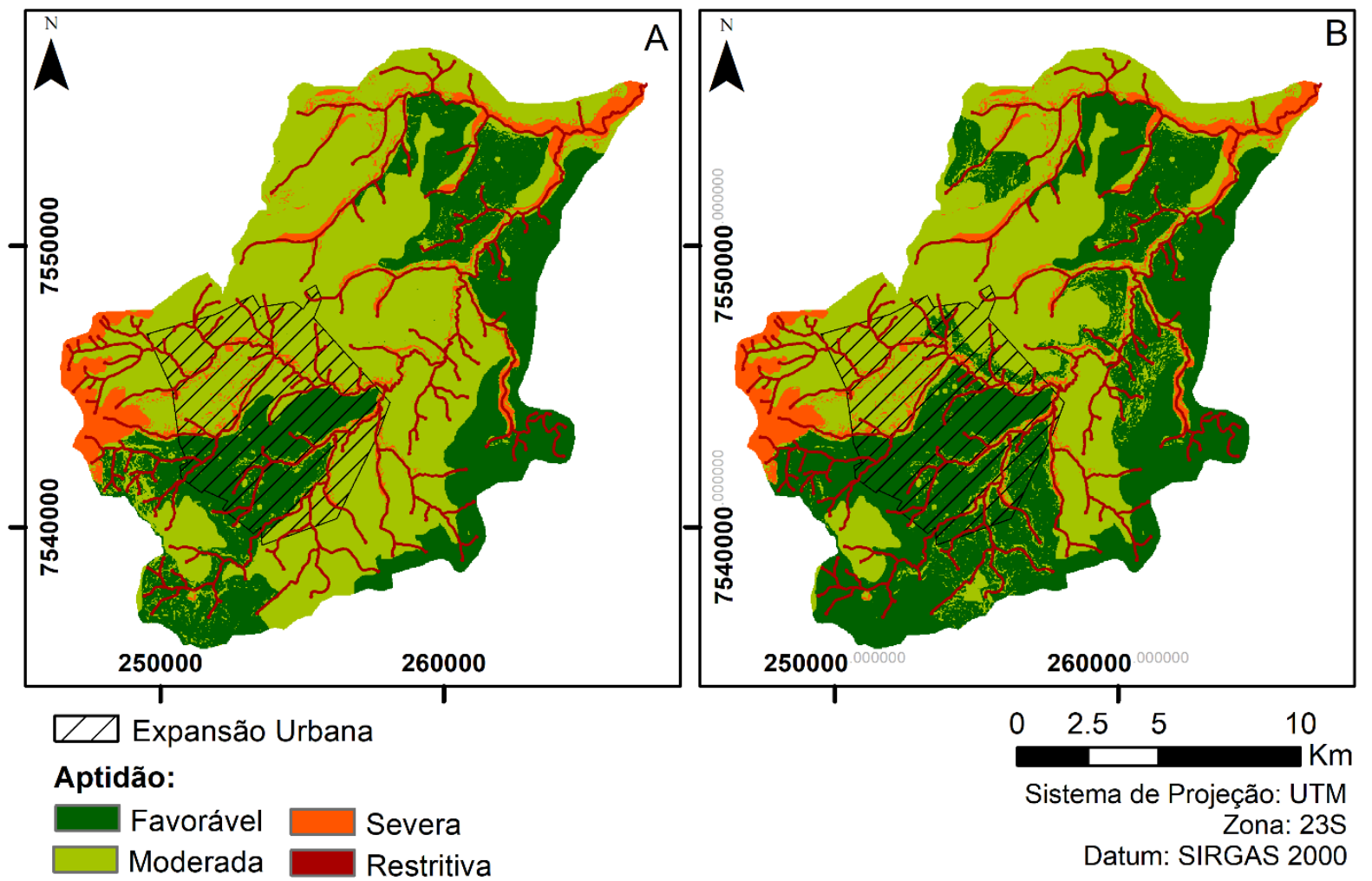

Figura 6 - Cartas de aptidão para fossa e lagoas de disposição de águas residuárias (A), e para tanques sépticos (B). Fonte: Autores (2020).

Nas parcelas leste, sul e norte (exceto ao longo dos cursos d'água) encontram-se as regiões mais favoráveis para a implantação de Tanques Sépticos, Lagoas para Águas Residuárias e Fossas, conforme pode ser verificado na Figura 6. Nestes locais, predominam o substrato rochoso da Formação Corumbataí ao sul e Rochas Intrusivas Básicas a leste e norte.

0 material inconsolidado nestes locais é formado pelo Residual da Formação Corumbataí com espessura de 2 a 5 metros ao sul. Nas porções leste e parte do norte da área, o material inconsolidado das áreas favoráveis é formado pela unidade Residual de Magmatitos, que apresenta textura argilosa e possui uma espessura superior a 10 metros na porção leste e de 5 a 10 metros na porção norte. Ainda a norte, onde ocorre a unidade Arenosa Aluvionar as condições são favoráveis onde a espessura deste material supera os 10 metros.

Os resultados obtidos permitiram observar que a aplicação da proposta de Zuquette \& Gandolfi (2004) é viável para avaliar as condições do meio físico rural visando à implantação dos sistemas alternativos aqui considerados, mesmo quando não se tem a disposição todos os dados e informações previstos na proposta.

Tendo em vista a necessidade de proteção dos solos e águas da contaminação (Associação Brasileira de Normas Técnicas, 1992, 1997; Companhia de Saneamento Básico do Estado de São Paulo , 2009; Brasil, 2014; Silva, 2014), os benefícios adicionais como o eventual uso dos efluentes na irrigação (Novaes et al., 2002; Brasil, 2014), e as questões socioeconômicas já apresentadas (Costa \& Guilhoto, 2011a, 2011b, 2014), a proposta se mostrou eficaz para o processo inicial de zoneamento do meio, permitindo que outros atributos mais específicos dos solos locais (especialmente relacionados às condições de drenagem) possam ser levantados numa etapa posterior, quando a comunidade ou $o$ empreendedor tiverem os recursos para implantação dos sistemas.

Com vistas a apresentar os resultados na forma de um único produto cartográfico, foi elaborada uma carta indicando a aptidão às soluções alternativas de esgotamento sanitário como um todo (Figura 7). 
Considerando as necessidades especificas dos moradores da zona rural, se observa que grande parcela da área foi classificada como favorável ou moderada, com exceção das áreas de fundos de vale em toda a bacia e cabeceiras de drenagem na porção oeste da área. Ora, como tais áreas usualmente são áreas de proteção ou áreas de ocupação controlada ou restrita, é lícito dizer que os moradores rurais da bacia se encontram em áreas com grande potencial de implantação dos sistemas alternativos.

A Figura 8 representa as porcentagens de ocorrência das classes de aptidão encontradas na área, com a primeira ilustração (Figura 8A) apresentando os resultados para toda a Bacia Hidrográfica, e a segunda (Figura 8B) apenas as áreas aplicáveis (excluindo-se Macrozona Urbana, Expansão Urbana, Proteção Ambiental e Zona Especial do Aeroporto).

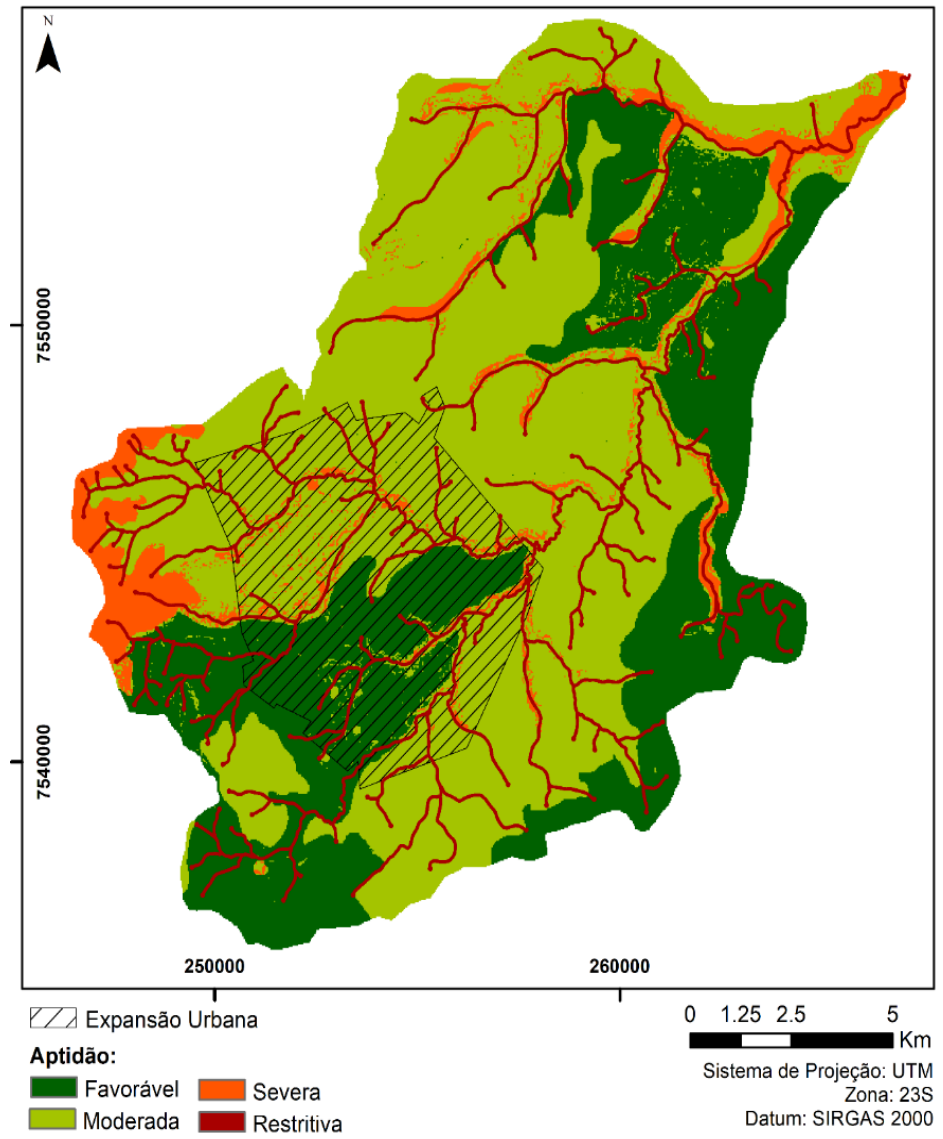

Figura 7 - Carta de aptidão para sistemas alternativos de esgotamento sanitário. Fonte: Autores (2020)
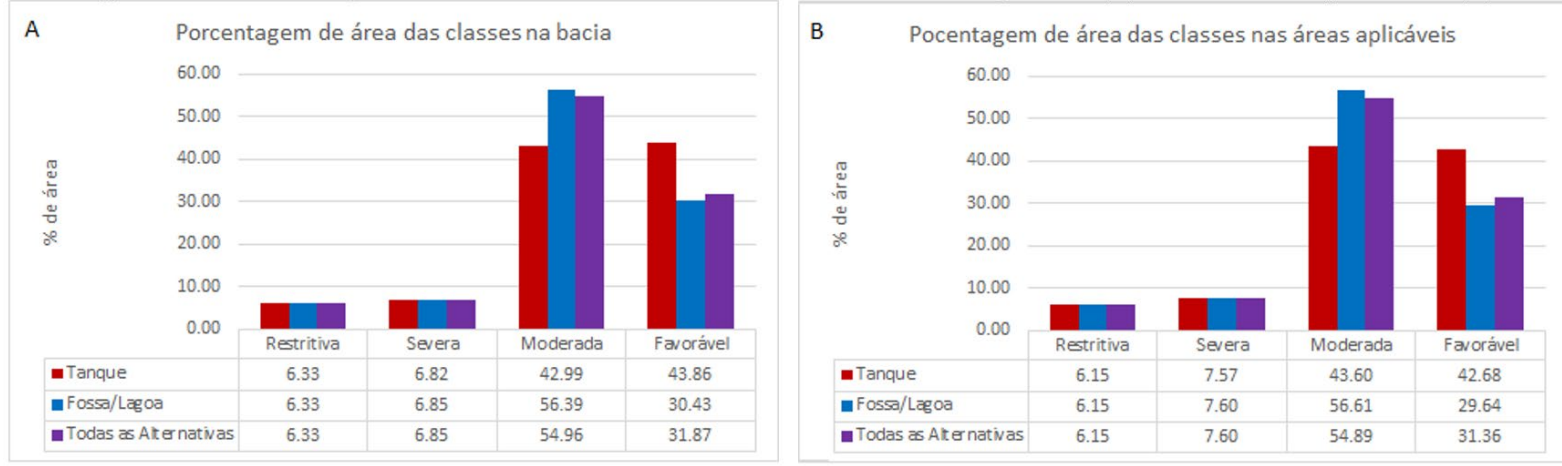

Figura 8 - Porcentagens de ocorrência das classes, na Bacia Hidrográfica (A) e nas áreas aplicáveis (B). Fonte: Autores (2020)

Considerando apenas as áreas aplicáveis, percebe-se uma redução da classe restritiva, que fica limitada às Áreas de Preservação Permanente (APP), com as áreas da classe severa resultando valores próximos de $8 \%$. A distribuição das classes moderada e favorável para tanques sépticos demonstrou 
valores próximos, sendo 46,46 e 45,47\%, respectivamente. Para fossas e lagoas a variação das classes foi maior, sendo predominante a ocorrência da classe moderada com 60,32\% e 31,58\% para a favorável.

Considerando a bacia hidrográfica em sua totalidade, conforme pode ser visto na Figura 8, também não ocorre registro de áreas restritas, e a ocorrência da classe severa se aproxima de 7,50\% para todas as técnicas. A distribuição das classes moderadas e favoráveis para tanques sépticos foi de 46,36 e 46,17\%, respectivamente. Já para fossas e lagoas de águas residuárias os valores encontrados foram de 60,59\% e 31,91\% para as condições moderadas e favoráveis, respectivamente.

A comparação entre as ilustrações da Figura 8 permite verificar que, apesar da exclusão das áreas não aplicáveis, a proporção da distribuição das classes mantém-se similar.

Os altos percentuais de áreas da bacia aptas à implantação das três alternativas (classes favorável e moderada) são consequência de condições favoráveis ou moderadas de importantes atributos como declividade, condições dos materiais inconsolidados, clima, feições geodinâmicas, e condições de circulação de água. As restrições à implantação de tais alternativas na área se limitam mais aos atributos do substrato rochoso.

Considerando apenas os atributos do meio físico, Costa et al. (2018) encontraram resultados similares ao analisarem as condições da área para implantação de aterros sanitários. Mesmo levando em conta as limitações logísticas para implantação de aterros sanitários, o trabalho citado obteve um percentual de 43,70\% da área classificada como favorável ou moderada. Também no caso desses autores, as condições do relevo de materiais inconsolidados se mostraram determinantes em tal classificação.

Ao caracterizar as condições ambientais da bacia do Ribeirão do Meio, Sardinha (2005) já havia apresentado resultados da mesma natureza. Ao elaborar uma Carta para Implantação de Empreendimentos Potencialmente Poluidores na bacia, o autor obteve uma classificação com predomínio das classes "alta" e "média" aptidão em mais de 60\% da área da bacia.

Em bacia hidrográfica limítrofe à do Ribeirão do Meio, as mesmas condições do meio físico (relevo, substrato rochoso e materiais inconsolidados) predominando, Piga et al. (2017) classificaram $46 \%$ da área como muito baixo, baixo e médio potencial de contaminação das águas subterrâneas, refletindo também condições favoráveis à implantação de empreendimentos da natureza daqueles aqui propostos.

\section{CONCLUSÕES}

Mesmo se considerando a semelhança dos resultados, fruto do uso dos mesmos componentes ambientais, e muitas vezes os mesmo atributos, as cartas de aptidão produzidas não indicam qual das técnicas representa a solução mais adequada (Tanques Sépticos, Fossas e Lagoas de Disposição de Águas Residuárias), mas indicam os locais mais favoráveis para a implantação de cada uma das alternativas. Decisões de projeto e construção, obviamente devem considerar levantamentos locais de detalhe e avaliações de impactos ambientais.

A proposta de Zuquette \& Gandolfi (2004) se mostrou eficaz para a avaliação realizada na escala regional (1:50.000), mesmo na condição em que não se tinham todas as informações necessárias consideração de atributos, de forma que atributos mais específicos possam ser levantados numa etapa posterior, em escala de detalhe e projeto.

De uma área total de 249,05 km², 200,37 km² se encontram na Macrozona Rural, sem acesso à rede coletora de esgoto. Neste contexto, as cartas de aptidão representam importante instrumento para subsidiar análises e tomada de decisão para áreas não contempladas por serviço de coleta e tratamento de esgoto, o que pode resultar na disposição de esgoto in natura nos cursos d'água ou em fossas negras.

0 atributo profundidade do substrato rochoso foi o que apresentou maior influência nos resultados de aptidão, isso é bastante compreensível quando se considera que o mesmo limita métodos construtivos e que, na área, controla a profundidade no nível freático.

De acordo com a metodologia proposta e considerando a escala dos dados de entrada, não foram encontradas áreas restritivas para a implantação das soluções aqui consideradas. Apenas $8 \%$ do território apresentam condições severas.

A aptidão moderada é predominante para a instalação de Tanques Sépticos, $60,32 \%$, sendo ainda 31,58\% favorável. Para Fossas e Lagoas de Águas Residuárias, esses números são, respectivamente, $46,46 \%$ e $45,47 \%$. 
Do ponto de vista socioeconômico, se observa que grande parcela da área foi classificada como favorável ou moderada, permitindo atender aos os moradores rurais da bacia com soluções eficazes e de menor custo.

Por terem sido desenvolvidas a partir das características físicas da bacia hidrográfica em uma escala 1:50.000, estas Cartas apresentam informações preliminares. Elas contêm informações importantes no âmbito do planejamento, apoiando a tomada de decisão, contudo, necessitando de levantamentos mais detalhados in loco para as implantações destas instalações.

O levantamento detalhado deve consistir de ensaios de campo e laboratório a serem realizados nos solos dos locais de interesse do poder publico ou dos moradores da zona rural visando determinar condições de infiltração e drenagem e características químicas dos solos quanto à capacidade de retenção de contaminantes.

\section{AGRADECIMENTOS}

Este trabalho foi realizado com apoio do Conselho Nacional de Desenvolvimento Científico e Tecnológico (CNPq) e da Coordenação de Aperfeiçoamento de Pessoal de Nível Superior - Brasil (CAPES) - Código de Financiamento 001.

\section{REFERÊNCIAS}

Agência Nacional de Águas e Saneamento Básico - ANA. (2019). Saneamento. Brasília: ANA. Recuperado em 11 de setembro de 2019, de https://www.ana.gov.br/aguas-no-brasil/saiba-quem-regula/saneamento\#wrapper

Alvares, A. C., Stape, J. L., Sentelhas, P. C., Gonçalvez, J. L. M., \& Sparovek, G. (2014). Köppen's climate classification map for Brazil. Meteorologische Zeitschrift, 22(6), 711-728.

Andrade, C. F., Sperling, M. V., \& Manjate, E. S. (2017). Treatment of septic tank sludge in a vertical flow constructed wetland system. Engenharia Agrícola, 37(4), 811-819. http://dx.doi.org/10.1590/1809-4430-eng.agric.v37n4p811$819 / 2017$

Associação Brasileira de Normas Técnicas - ABNT. (1992). ABNT NBR 12209: projeto de estações de tratamento de esgoto sanitário (12 p.). Rio de Janeiro: ABNT.

Associação Brasileira de Normas Técnicas - ABNT. (1997). ABNT NBR 13969: tanques sépticos: unidades de tratamento complementar e disposição final dos efluentes líquidos: projeto, construção e operação (60p.). Rio de Janeiro: ABNT.

Brasil. (2014). Manual de orientações técnicas para elaboração de propostas para o Programa de Melhorias Sanitárias Domiciliares - Funasa. Brasília: Fundação Nacional de Saúde.

Centro Integrado de Informações Agrometereológicas - CIIAGRO. (2009). São Paulo. Recuperado em 10 de junho de 2021, de http://www.ciiagro.sp.gov.br/climasp.html

Cheng, P., Jin, Q., Jiang, H., Hua, M., \& Ye, Z. (2020). Efficiency assessment of rural domestic sewage treatment facilities by a slacked-based DEA model. Journal of Cleaner Production, 267, 122111. http://dx.doi.org/10.1016/j.jclepro.2020.122111

Christopherson, S.H. (2001). Alternative on-site sewage treatment systems. BioCycle, 42(9), 30-33.

Companhia de Saneamento Básico do Estado de São Paulo - SABESP. (2009). NTS 230: projeto de lagoas de estabilização e seu tratamento complementar para esgoto sanitário (35 p.). Rio de Janeiro: Companhia de Saneamento Básico do Estado de São Paulo.

Conselho Federal de Administração - CFA. (2019). Mais da metade das obras paradas no país são de saneamento. Brasília: CFA. Recuperado em 12 de setembro de 2019, de https://cfa.org.br/mais-a-metade-das-obras-paradas-no-pais-saode-saneamento/.

Cornelli, R. (2014). Análise e seleção de alternativas sustentáveis de esgotamento sanitário (Dissertação de mestrado). Universidade Federal do Rio Grande do Sul.

Costa, C. C., \& Guilhoto, J. J. M. (2011a). Saneamento Rural Básico no Brasil: uma análise de impacto da proposta impacto da fossa séptica biodigestora. In Anais do XIV Encontro Nacional de Economia Política (Cadernos de Resumos. CDROM). Uberlândia: Sociedade Brasileira de Economia Política.

Costa, C. C., \& Guilhoto, J. J. M. (2011b). Impactos sociais, econômicos e ambientais da melhoria do saneamento rural básico no Brasil. In Anais do IX Encontro da Sociedade Brasileira de Economia Ecológica (CD-ROM). Brasília: Sociedade Brasileira de Economia Ecológica.

Costa, C. C., \& Guilhoto, J. J. M. (2014). Saneamento rural no Brasil: impacto da fossa séptica biodigestora. Engenharia Sanitaria e Ambiental, 1, 51-60. 
Costa, C. W., Lorandi, R., Lollo, J. A., Serikawa, V. S., Ferreira, T. S., Stanganini, F. N., \& Gonçalves Neto, P. S. (2018). Análise multicritério aplicada à seleção de áreas para implantação de aterros sanitários na Bacia do Ribeirão do Meio (Leme, SP), em escala 1: 50.000. Revista Sociedade. Natureza, 30(1), 205-227.

Failache, M., \& Zuquette, L. (2015). Avaliação geológica e geotécnica preliminar da degradação ambiental das áreas úmidas na região de Leme-Brasil. Revista de Geología Aplicada a la Ingeniería y al Ambiente, 35(35), 17-34.

Galindo, N., Silva, W. T. L., Novaes, A. P., Godoy, L. A., Soares, M. T. S., Galvani, F., Marmo, C. R., \& Romero, P. A. L. (2019). Perguntas e respostas: fossa séptica biodigestora edição revisada e ampliada. São Carlos: Embrapa.

Gu, B., Fan, L., Ying, Z., Xu, Q., Luo, W., Ge, Y., Scott, S., \& Chang, J. (2016). Socioeconomic constraints on the technological choices in rural sewage treatment. Environmental Science and Pollution Research International, 23(20), 2036020367. http://dx.doi.org/10.1007/s11356-016-7267-z

Hasui, Y. (2012). Compartimentação Geológica do Brasil. In Y. Hasui, C. D. R. Carneiro, F. F. M. Almeida, \& A. Bartorelli (Orgs.), Geologia do Brasil. São Paulo: BECA, pp. 112-122.

Instituto Brasileiro de Geografia e Estatística - IBGE. (2010). Sinopse do censo demográfico. Rio de Janeiro: IBGE. Recuperado em 26 de outubro de 2020, de https://censo2010.ibge.gov.br/sinopse/index.php?dados=29\&uf=35

Instituto Brasileiro de Geografia e Estatística - IBGE. (2020). Cidades e estados. Rio de Janeiro: IBGE. Recuperado em 26 de outubro de 2020, de https://www.ibge.gov.br/cidades-e-estados.html.

Instituto Trata Brasil. (2018). Saneamento rural: um enorme desafio para o Brasil. São Paulo. Recuperado em 11 de setembro de 2019, de http://www.tratabrasil.org.br/saneamento-rural-um-enorme-desafio-para-o-brasil--portaldo-saneamento?fbclid=IwAR0u_9-eRQJeH67DyM89YtfMFncfkPQIKaJSSp2puFK23in62SI34a2Tum0

Kalbar, P. P., Karmakar, S., \& Asolekar, S. R. (2012). Selection of an appropriate wastewater treatment technology: a scenario-based multiple-attribute decision-making approach. Journal of Environmental Management, 113, 158-169. http://dx.doi.org/10.1016/j.jenvman.2012.08.025

Landau, E. C., \& Moura, L. (2016). Índices de adequação do Saneamento Báisco no Brasil. In E. C. Landau \& L. Moura (Orgs.), Variação geográfica do saneamento básico no Brasil em 2010: domicílios urbanos e rurais. Brasília: Embrapa. pp. 149-167.

Leme. (2018a). Minuta de Lei Municipal: revisão do Plano Diretor de Desenvolvimento. Leme. Recuperado em 12 de setembro de 2019, de https://www.leme.sp.gov.br/pagina/9

Leme. (2018b). Minuta de Lei Municipal: revisão do Plano Diretor de Desenvolvimento (Anexo I: Macrozoneamento). Leme. Recuperado em 12 de setembro de 2019, de https://www.leme.sp.gov.br/pagina/9

Li, Y., Lin, C., Wang, Y., Gao, X., Xie, T., Hai, R., Wang, X., \& Zhang, X. (2017). YMulti-criteria evaluation method for site selection of industrial wastewater discharge in coastal regions. Journal of Cleaner Production, 161, 1143-1152. http://dx.doi.org/10.1016/j.jclepro.2017.05.030

Lollo, J. A. (1991). Mapeamento geotécnico da Folha de Leme - SP (Dissertação de mestrado). Escola de Engenharia de São Carlos, Universidade de São Paulo.

Lopes, M. S., \& Saldanha, D. L. (2016). Análise de vulnerabilidade natural à erosão como subsídio ao planejamento ambiental do oeste da Bacia Hidrográfica do Camaquã - RS. Revista Brasileira de Cartografia, 68(9), 1689-1708.

Lorandi, R., \& Lollo, J. A. (2016).Zoneamento geoambiental analítico da bacia do Rio Claro (SP) na escala 1:50.000 (100 p., Relatório de Pesquisa. Processo 2013-03699-5). São Carlos: Fundação de Amparo à Pesquisa do Estado de São Paulo (FAPESP).

Lu, S., Zhang, X., Wang, J., \& Pei, L. (2016). Impacts of different media on constructed wetlands for rural household sewage treatment. Journal of Cleaner Production, 127, 325-330. http://dx.doi.org/10.1016/j.jclepro.2016.03.166

Massoud, M. A., Tarhini, A., \& Nasr, J. A. (2009). Decentralized approaches to wastewater treatment and management: applicability in developing countries. Journal of Environmental Management, 90(1), 652-659. http://dx.doi.org/10.1016/j.jenvman.2008.07.001

Novaes, A. P., Simões, M. L., Martin Nete, L., Cruvinel, P. E., Santana, A., Novotny, E. H., Santiago, G., \& Nogueira, A. R. A. (2002). Utilização de uma fossa séptica biodigestora para melhoria do saneamento rural e desenvolvimento da agricultura orgânica. São Carlos: Embrapa.

Oldenkamp, R., Huijbregts, M. A. J., Hollander, A., \& Ragas, A. M. J. (2014). Environmental impact assessment of pharmaceutical prescriptions: does location matter? Chemosphere, 115, 88-94. http://dx.doi.org/10.1016/j.chemosphere.2014.01.012

Piga, F. G., Tão, N. G. R., Ruggiero, M. H., Marquezola, D. S., Boina, W. L. O., Costa, W. C., Lollo, J. A., Lorandi, R., Melanda, E. A., \& Moschini, L. E. (2017). Multi-criteria potential groundwater contamination and human activities: araras watershed, Brazil. Revista Brasileira de Recursos Hídricos, 22, e56. 
Pinheiro, A., Schoen, C., Schultz, J., Heinz, K. G. H., Pinheiro, I. G., \& Deschamps, F. C. (2014). Relação entre o uso do solo e a qualidade da água em bacia hidrográfica rural no Bioma Mata Atlântica. Revista Brasileira de Recursos Hídricos, 19(3), 127-139.

Ross, J. L., \& Moroz, S. I. C. (1997). Mapa geomorfológico do Estado de São Paulo (Escala 1:500.000). São Paulo: FFLCHUSP/IPT/FAPESP.

Sardinha, D. S. (2005). Avaliação da qualidade da água e diagnóstico ambiental na bacia hidrográfica do Ribeirão do Meio, Leme (SP) (Trabalho de conclusão de curso). Faculdades COC, Ribeirão Preto.

Silva, M. S. L., Mathiesen, A., Brito, L. T. L., Lima, J. E. F. W., \& Carvalho, C. J. R. (2018). Água e saneamento: contribuições da Embrapa. Brasília: Embrapa.

Silva, W. T. L. (2014). Sistemas biológicos simplificados aplicados ao saneamento básico rural. In J. M. Naime, L. H. C. Mattoso, W. T. L. Silva, P. E. Cruvinel, L. Martin-Neto \& S. Crestana (Orgs.), Conceitos e aplicações da instrumentação para o avanço da agricultura (pp. 177-210). Brasília: Embrapa.

Soares, S. R. A., Bernardes, R. S., \& Cordeiro Netto, O. M. (2002). Relações entre saneamento, saúde pública e meio ambiente: elementos para formulação de um modelo de planejamento em saneamento. Cadernos de Saude Publica, 18(6), 1713-1724. http://dx.doi.org/10.1590/S0102-311X2002000600026

Souza, L.A., \& Sobreira, F.G. (2015). Procedimentos para Elaboração de Cartas Geotécnicas no Planejamento Urbano. Revista Brasileira de Cartografia, 67(1), 141-156.

Strahler, A. N. (1952). Hypsometric (area-altitude) analysis of erosional topography. Geological Society of America Bulletin, 63(11), 1117-1142. http://dx.doi.org/10.1130/0016-7606(1952)63[1117:HAAOET]2.0.C0;2

Urban, R. C., \& Isaac, R. L. (2018). WTP and WWTP sludge management: a case study in the metropolitan area of Campinas, southeastern Brazil. Environmental Monitoring and Assessment, 190(10), 584. http://dx.doi.org/10.1007/s10661-018-6972-0

Wójtowicz-Wróbel, A. (2018). Accessibility of sewage treatment plants: benefits and limitations associated with their locations requirements. E3s Web of Conferencies, 65, 05005.

Zuquette, L.V. (1987). Análise crítica da cartografia geotécnica e proposta metodológica para as condições brasileiras (Tese de Doutorado). Escola de Engenharia de São Carlos, Universidade de São Paulo.

Zuquette, L. V., \& Gandolfi, N. (2004). Cartografia geotécnica. São Paulo: Oficina de Textos.

\section{Contribuições dos autores:}

Tatiane Ferreira Olivatto: desenvolvimento da etapa metodológica, a análise dos resultados e escrita do artigo.

João Mateus Marão Domingues: desenvolvimento da etapa metodológica, a análise dos resultados e escrita do artigo.

Guilherme Sarausa de Azevedo: desenvolvimento da etapa metodológica, a análise dos resultados e escrita do artigo.

Franciane Mendonça dos Santos: a caracterização da área de estudo e validação dos resultados cartográficos.

José Augusto Di Lollo: delimitação da metodologia, análise dos resultados e revisão do artigo.

Reinaldo Lorandi: delimitação da metodologia, análise dos resultados e revisão do artigo.

Luiz Eduardo Moschini: delimitação da metodologia, análise dos resultados e revisão do artigo. 